\title{
Is Child Advertising Inherently Unfair?
}

\author{
David Rowthorn ${ }^{1}$
}

Received: 22 March 2017 / Accepted: 13 November 2017 / Published online: 23 November 2017

(c) The Author(s) 2017. This article is an open access publication

\begin{abstract}
Child advertising is routinely accused of being inherently unfair. This is normally based on the claim that younger children do not understand advertising's selling intent, a claim that is well supported by the available evidence. But the argumentation that gets us from this claim to inherent unfairness has been largely ignored. This article addresses this gap in the literature by considering two accounts of fairness as candidates for understanding child advertising: the process-exclusive account and the inclusive account. The article argues for the rejection of the process-exclusive account (where the process is all that matters) on the basis that it ends up condemning acceptable, non-commercial persuasion. The article then examines the candidates for the negative outcome of child advertising that is required for unfairness on the inclusive account. It concludes that the evidence for each being inherent to child advertising is currently insufficient to support the conclusion that child advertising is inherently unfair.
\end{abstract}

Keywords Child advertising · Unfairness · Consumer vulnerability · Persuasion · Ethics · Advertising regulation

In 1978, the US Federal Trade Commission (FTC), under pressure from concerned parent groups, proposed a ban on television advertising of high-sugar foods aimed at under$12 \mathrm{~s}$, and all advertising aimed at under-8 (Beales 2003). The FTC failed to push this legislation through. But the opposition to advertising for unhealthy food persisted and, in 2007, the UK Advertising Standards Authority banned advertising of HFSS food (food high in fat, salt or sugar) on television; this was extended to non-broadcast media in July 2017. While unhealthy food has become the public face of adversity to child advertising, surveying the past few decades reveals that the other prong of that FTC rulemaking attempt, which sought to ban all advertising to under-8s, left its own mark on discussions of child advertising. The practice was banned in Quebec in 1980, Sweden and Norway in the early 1990s, and, most recently Brazil in 2014.

The FTC originally argued that advertising to children too young to understand advertising's persuasive or selling intent is inherently unfair and deceptive. ${ }^{1}$ This argument has persisted in the work of academics, campaign groups and cultural critics. The case for advertising's inherent unfairness is almost exclusively based on the premise that

David Rowthorn

D.W.Rowthorn@warwick.ac.uk

1 University of Warwick, Coventry, UK children below a certain age do not understand that advertising is selling to them. But while that premise is continually strengthened and refined in the empirical literature, the argument that gets us from that to the inherent unfairness claim - including the concept of fairness being used-has received little attention. This article lays out a framework of fairness and uses this to determine whether child advertising is, in fact, inherently unfair. It concludes that we are not currently in a position to substantiate that accusation, but it also outlines the most likely candidates for future research that could support such a conclusion.

The article begins by outlining two ways to understand fairness in the context of child advertising. One is the process-exclusive account, on which child advertising is unfair irrespective of outcome; the other is the inclusive account, according to which child advertising must at least carry the risk of negative outcomes to be unfair (it must include both a flawed process and a harmful outcome). The article then discusses what it means for unfairness to be inherent. Next, it argues for the rejection of the process-exclusive account on the grounds that it leads us to condemn perfectly acceptable non-commercial persuasion. Having adopted the inclusive account, the rest of the article is dedicated to discussing candidates for negative outcomes that might be inherent to child advertising. This reveals some reasons to think that

${ }_{1}$ At that time, the distinction between persuasive intent and selling intent was not formally recognised. 
certain negative harms might be inherent to advertising, but also highlights gaps that need to be filled and connections that need to be strengthened before such a conclusion can be drawn. The article concludes that we are not in a position to declare child advertising inherently unfair, but that there are some key questions which, depending on their answers, might well ground such an accusation.

\section{Fairness}

Child advertising is an interaction between advertiser and child. We can think of this interaction as a persuasive episode, a sales pitch, or a form of market exchange. What makes such interactions unfair? There are broadly two ways to answer this. We can locate unfairness in the process of the interaction, or we can locate it in the outcome. A third possibility is to hold both of these to be necessary conditions of fairness, such that an unfair interaction must involve a flawed process giving rise to negative outcome. This gives us three views, which can be termed the process-exclusive view, the outcome-exclusive view and the inclusive view. This echoes the use of these terms in discussions of fairness as it features in the philosophical literature on exploitation (Jansen and Wall 2013). For the purpose of this article, we will assume that child advertising involves a flawed process, accepting the premise that children cannot engage with advertising as adults can (we will look more closely at this premise later). This commitment is ubiquitous in the child advertising debate. The question, then, is whether outcome also matters. Should we adopt a process-exclusive account or an inclusive account? And what follows either way?

While this looks like a straightforward decision, the literature on unfairness in child advertising is characterised by stubborn ambiguity on this issue. This is likely because so little conceptual work on fairness has made its way into the debate. The most notable attempt to provide a concept of fairness that applies to child advertising is Brenkert's (1998) discussion of marketing to vulnerable populations. While not dealing exclusively with child advertising, Brenkert's characterisation of vulnerability does apply to them and he spends some time dealing directly with child marketing. Yet his view in that article is a perfect example of the ambiguity about whether outcomes are necessary for unfairness. Brenkert (1998, p. 301) first defines marketing unfairness in process terms. He lays out the following five necessary conditions for an individual to be a competent consumer:

A. Knowledge they should shop around and are able to do so

B. Competence to determine differences in quality and best price

C. Awareness of their legal rights
D. Knowledge of the products and their characteristics

E. Resources to enter into market relations

He goes on to tie these to fairness, claiming that "when these conditions are fulfilled (ceteris paribus), market relations between market participants and clients will be fair or just". This makes no reference to a market interaction's outcome, only its process. But Brenkert's main concern is with what he calls "special vulnerability", which he sees as a matter of being susceptible to harm as a result of features of oneself that are beyond one's control. He goes on to connect vulnerability to fairness as follows:

Accordingly, when market participants face individuals who do not qualify or pass a certain threshold for market competition, the latter are unable to protect their interests in a manner comparable to that of ordinary market clients... when this situation arises because these individuals have special vulnerabilities then to market to them in ways which take advantage of their vulnerabilities, i.e., to seek to engage them in the competitive effort to sell them goods through the weaknesses characterizing their vulnerabilities, is to treat them unfairly. Regardless of whether they are actually harmed, they are being taken advantage of. (Brenkert 1998, p. 303)

Again, Brenkert seems to commit to a process-exclusive account. He clearly excludes negative outcome as a necessary condition of unfairness. But he also builds negative outcomes into his understanding of vulnerability. To be vulnerable is, partly, to be susceptible to harm; and in the above passage, vulnerability is a matter of not being able to protect one's interests. It is not clear how children's interests, which are a matter of outcome, relate to the process of taking advantage of their market incompetence. We will revisit Brenkert's account in more detail in "The Process-Exclusive Account" section. For now, it is sufficient to flag up the difficulty in categorising his view as either process-exclusive or inclusive.

The other notable engagement with unfairness in child advertising is an influential 2004 report by a task force assembled by the American Psychological Association (APA) to examine child advertising (Kunkel et al. 2004). This report builds on key ideas first outlined in that 1978 FTC attempt to ban child advertising (FTC 1978). The APA report defends the view that advertising to children too young to understand its selling intent is inherently unfair. It explicitly separates fairness from harm, claiming that even in cases where child advertising is benign, "an alternative perspective must be taken into account, one that involves weighing the fundamental fairness of advertising to young children given the well-documented limitations in their ability to recognise and defend against commercial persuasion" 
(Kunkel et al. 2004, p. 21). It should be noted that the report does not concede the premise that child advertising is harmless, or even that it can be. It simply claims that it would not matter, because fairness is the issue, not harm. Thus, they see the process of child advertising as sufficient to label it unfair, irrespective of its outcome.

Buijzen and Valkenburg (2003, p. 438) note a tendency among critics of child advertising to cite either the unfairness or the harm of the practice. This, again, represents a distinction between process and outcome. But not everyone holds this view. Nairn (2014, p. 2033) claims that "If something is unfair to children, then it clearly detracts from their wellbeing". This suggests that a negative outcome is a necessary condition of unfairness. But Nairn does not develop the concept of fairness further, instead focussing on the empirical work into children's understanding of advertising. This is a familiar feature of the literature and something to which we return in "Inherentness" section.

We need to separate the process-exclusive and the inclusive accounts and deal with them separately; that is the task of "The Process-Exclusive Account" and "The Inclusive Account" sections. But before deciding whether to include negative outcome as a necessary condition of fairness, we need to be clear on what it means for outcome to feature. Does a negative outcome need to be guaranteed, or is it sufficient for there to be a risk of a negative outcome?

\section{Outcome As Risk}

Perhaps the biggest lacuna in the literature on child advertising unfairness is the failure to distinguish between outcomes and risked outcomes. Building in risk makes inclusive views more attractive when we talk about inherent unfairness. If we only label advertising unfair when it compromises wellbeing, the claim that it is inherently unfair is relatively easy to refute. All we need do is find one benign child advert. If, however, we do not require a negative outcome, but only the risk of one, then it is a lot more plausible to label child advertising inherently unfair. This is because even when an advert turns out to be harmless, exposing the child to the advertiser could still be said to risk a negative outcome.

We will discuss the notion of inherentness soon, but for now it is worth fleshing out this notion of risked outcome. The following imaginary example helps get this started:

Repentant cheat: just before the big championship match, a boxer secretly spikes his opponent's water with a mild sedative. The first round takes a heavy toll on the spiked fighter. At the start of the second round, the cheat has a change of heart and walks away from the fight, leaving his sedated opponent the victor.

In repentant cheat, the victim of the spiking was left vulnerable to defeat, but the cheat did not take advantage of this fact. Side effects of the sedative aside, the outcome was positive for the spiked boxer. But nobody would deny that this was an unfair fight from the first bell.

Repentant cheat appears to vindicate the process-exclusive account, since unfairness is present irrespective of outcome. It is the set-up, not the result, that makes the fight unfair. This example is apt for child advertising, since it too involves the idea of being able to defend oneself, or "fighting back" against advertisers' persuasion attempts. But repentant cheat needs to be interpreted cautiously. Just because a negative outcome did not materialise does not mean outcome is irrelevant. The cheat put his opponent in a position to be taken advantage of in a way that would leave him worse off-which is to say, he put him at risk. Risk in this case arises as the result of a combination of opportunity and motive. The cheat had the opportunity to take advantage of his opponent's vulnerability and was motivated to do so. Together, these meant that he was likely to do so. When one relies on the likelihood of a certain outcome, one's account is no longer process-exclusive.

It should be noted that giving someone the opportunity to harm children is not sufficient for unfairness. If it were, then parenting itself would be unfair, since parents regularly have the opportunity to take advantage of children's vulnerability. We assume that they are motivated by the children's interests, not by, say, profit. As such, they are sufficiently unlikely to act against those children's interests.

The literature on this topic has not been sensitive to this distinction, such that in some cases, those who appear to subscribe to process-exclusive views might well opt for inclusive views once we allow that outcome can be understood in terms of risk. The APA report, for example, could be read as claiming that despite the possibility of individual benign advertising encounters, the risks inherent to child advertising make it unfair. Perhaps even Brenkert would assent to this view.

In summary, on a process-exclusive account, child advertising is unfair if there is a flaw in the process of the advertising interaction, even if this fails to lead to a negative outcome or poses a sufficient risk. On an inclusive account, child advertising is unfair if its process is flawed such that the child is negatively affected or is sufficiently likely to be. With this basic distinction mapped, we can now turn the question of inherentness. What would it mean for child advertising to be inherently unfair?

\section{Inherentness}

The idea of inherent unfairness suggests a few things: that a practice cannot be done fairly under any circumstances; that features constitutive of that practice make it unfair; that to make a practice fair, one would have to make it a different 
practice entirely. If one adopts a process-exclusive account of unfairness to talk about child advertising, then the claim would be that some feature inherent to the practice prevents it being a fair interaction. On the inclusive view, the claim could be that an inherent feature of advertising means that every child advert has a negative outcome or at least risks one.

Whichever account we adopt, the inherentness of unfairness needs to be located somewhere in the advertising interaction. The most common place to locate inherent unfairness is in children's limited understanding of the nature of advertising. This understanding is constrained by features inherent to children of the relevant age. This has been the central premise of the child advertising debate since at least the FTC's 1978 attempt to ban the practice. It was well supported at that time and was built upon in the decades that followed (John 1999). The consensus is that before age eight, the majority of children do not understand advertising's selling intent (Kunkel et al. 2004; Oates et al. 2002). Between eight and ten, children are still learning to assess persuasive intent, which adds to selling intent an appreciation of advertising tactics and a recognition that adverts change behaviour by changing attitudes (Carter et al. 2011; Kunkel et al. 2004, p. 21). The development of these abilities is constrained by more fundamental mental traits, such as theory of mind (Lapierre 2015). This development can only be expedited so much; hence, children at a certain age simply cannot be taught to identify selling or persuasive intent.

On the process-exclusive account, children's limited understanding might be enough to secure inherent unfairness, since one might hold a view such that all fair advertising encounters presuppose a certain level of audience competence. Alternatively, one might think that only certain kinds of advertising, in combination with children's limited understanding, constitute a flawed process. This is what Brenkert commits to in the end, although his initial demands on fairness suggest that all child advertising would be unfair.

On the inclusive account, children's inherent lack of understanding is insufficient to secure the claim that child advertising is inherently unfair. Children are inherently vulnerable to advertising, but, as repentant cheat shows, this vulnerability must be coupled with the risk of a negative outcome. That is, child advertising as a practice must threaten to take advantage of children's vulnerabilities in a way that risks leaving them worse off. We might concede that child advertising as it is now threatens children-some adverts harm them. The question is: is this threat inherent to child advertising? In other words, on the inclusive view, we require inherentness on both sides of the audience-advert divide. Brenkert comes close to this idea when he defines vulnerability as a relation, writing "it is the combination of their special characteristics and the means or techniques which marketers use that render them specially vulnerable.
This emphasises the relational nature of vulnerability" (Brenkert 1998, p. 303).

The need to talk about what is inherent to adverts themselves has been overlooked in the debate because inherentness is almost always located in children's understanding of adverts. It has been taken as a given that this is sufficient to make the practice unfair. This can partly be explained by the failure to distinguish process-exclusive and inclusive views of fairness. As we have just seen, the view one adopts drastically shifts the requirements for labelling child advertising unfair.

At this point, we have identified two things that need to be done before we can determine whether child advertising is inherently unfair. First, we need to assess the processexclusive account, since adopting some variants of that view would conclude the argument with nothing more than the premise that children do not understand advertising. But if we reject the process-exclusive view in favour of the inclusive view, then we face a second task: to discuss the best candidates for inherent features of advertising that guarantee, or at least make sufficiently likely, negative outcomes for children. These two tasks comprise the next two sections, and the remainder, of this article.

\section{The Process-Exclusive Account}

On Brenkert's view, the process of child advertising is flawed when advertisers take advantage of children's vulnerability to commercial persuasion, negative outcome or otherwise. Children are vulnerable to persuasion because they do not understand how they are persuaded. But this makes Brenkert's position very restrictive, since children at the age we are talking about fail to understand all advertising persuasion. If understanding is the test of vulnerability, then it would seem that no child advertising is fair.

Locating the flaw in the process of child advertising in children's failure to understand persuasion is, however, subject to the following objection. We persuade children of many things, whether this takes the form of parental persuasion or societal persuasion through such things as Public Service Announcements (PSAs) and campaigns. Parents persuade children to eat healthily by presenting food in a certain way, for example. PSAs persuade them not to litter using cartoon characters, just as cereal companies persuade them to ask for a certain brand of cereal using mascots. On the view described, these forms of persuasion fail the fairness test. Children do not understand how they are being persuaded and are not able to defend against that persuasion. Parents, teachers and the government all take advantage of this vulnerability in order to persuade children to behave in certain ways. Indeed, the very reason they do this is that 
children cannot be reason in the way adults can-which is partly why they defenceless in the first place.

Describing, for example, parental persuasion in this way is odd indeed. Persuading a child to eat peas by arranging them in a smiley face lacks the sinister connotations of the phrase "taking advantage of their vulnerabilities". But this is not because the methods used by advertisers differ in any relevant way. Children are defenceless against parents and adults alike. It is not that children are defenceless against parents that is important, but what parents do in response to that defencelessness. In fact, to even describe children as "defenceless" against parents is to already assign ill will to parents, which we ordinarily take them not to have. With advertising, unlike parenthood, there is something children need to defend against.

We need to refer to something other than children's limited understanding in order to distinguish adverts from PSAs and the like. Brenkert recognises this need to separate advertising from PSAs, which he does by claiming that to even align them in the first place conflates...

...public messages solely for the good of the recipient and private messages for the good of the sender, which may also be good for the recipient. In short, if a group is specially vulnerable, the use of unfair techniques which would not ultimately cause them harm is still the use of techniques which treat such individuals unfairly through manipulating them through their vulnerabilities. Only in very special circumstances should such marketing techniques be employed. (Brenkert 1998, p. 306)

Brenkert runs together a number of points here. One has to do with the techniques used by advertisers, but we have just seen that this fails to distinguish advertising from other kinds of persuasion. He also refers to interests: adverts are primarily in the interests of the advertiser, whereas PSAs (and parental persuasion) are in the interests of the child. This makes advertising a different process altogether from these other kinds of persuasion.

This makes child advertising inherently unfair, since it requires of the practice something that it cannot deliver. If the flaw in the process of child advertising is that advertisers are motivated only by their own interests, then to make child advertising fair would require that advertisers be primarily motivated by children's interests. But they would not be advertisers if they were so motivated. Hence, it looks like child advertising is irredeemable.

The problem here is that the same is true of advertising aimed at adults. Let us assume, for the sake of argument, that advertisers are motivated exclusively by their own interests, not by those of consumers. ${ }^{2}$ Adults can defend advertising persuasion to a certain extent, but there are tactics advertisers can use to take advantage of consumers, such as outright deception or playing excessively on common fears. Such advertising is recognised to be unfair. But we do not regulate advertising to make it a fair interaction by changing advertisers' interests. We accept that advertisers are out for profit, but we curtail advertising that uses certain methods or has certain results. If the process of advertising were flawed simply by virtue of the interests involved, we would be powerless to make it fair, even in the adult case.

The other issue with talking about interests as the basis for unfairness is that interests are not really process-exclusive at all. To say that exposing defenceless children to those who do not have their interests at heart is unfair only makes sense if there is some threat of those interests being compromised. The process of child advertising is only unfair due to advertiser's interests because it exposes them to the risk of bad outcomes at the hands of advertisers. If this risk is mitigated, then it makes little sense to talk about it as a flawed process. Hence, we are really not concerned with a process-exclusive account, but with an inclusive account.

This raises a key point, which is that regulated advertising should not be compared with unregulated advertising. Of course it is true that advertisers unconstrained by regulation would take advantage of children-as they would adults. But tightly regulated advertising is not mere exposure of children to those who do not share their interests: it is supervised, filtered access that serves to nullify those instances where the advertiser's pursuit of their interests makes any difference. It is communication to which children are exposed only after it has been approved by those with children's interests at heart, just as adult advertising is that which has been approved by the relevant regulatory body. In short, talking about interests really amounts to talking about outcomes. It should be made very clear, however, that I am neither defending nor condemning current regulations. Advertising regulation is often placed in the hands of industry-funded bodies (Gunter et al. 2004), which might be thought a conflict of interest. However, the purpose of this article is to make the point that child advertising is not inherently unfair, and since industry self-regulation is only a contingent fact about certain jurisdictions, it does not affect that basic point. How advertising should be regulated is a separate question, although our discussion so far suggests that it should be in the hands of those with children's interests at heart.

\footnotetext{
2 This is, of course, an oversimplification and is unfair to advertisers. It also assumes that consumer interests and corporate interests are always at odds, which will, in a moment, be shown to be misleading. Nonetheless, this premise serves to highlight the strongest form of the interests argument and how that fails.
} 
We cannot distinguish advertising from PSAs or parental persuasion by appeal to the techniques used or to children's defencelessness against persuasion. But if we appeal to a difference of interests between advertisers and parents, then we raise the further question of why this difference of interests makes a difference to fairness. The answer to that lies in the risks posed to children by exposing them to advertisers, not in the simple fact that there are different interests. At this point, the process-exclusive account reveals itself to be inclusive of outcomes after all.

It is important to differentiate two claims here. One is that persuasion of children is inherently unfair, the other, that advertising to children is inherently unfair. It does not necessarily follow from the fact that child advertising is inherently unfair that persuading children is so. However, there must be something that makes child advertising inherently unfair. One candidate for that feature is persuasion. Advertising seeks to persuade children. Moreover, it seeks persuade them using techniques that they are not equipped to understand. The question is: is the persuasive nature of advertising sufficient to make it unfair? The reason I have proposed for answering this in the negative is that it requires us to condemn persuasion of children more broadly, which is far too strict. So we need an answer as to whether child persuasion is unfair in order to better understand the unfairness that is supposed to reside in child advertising.

If child advertising is not inherently unfair simply by being persuasive, there must be some feature of advertising that distinguishes it from other persuasion, such as that done by parents. One such feature is that advertisers seek material gain from children, whereas parents do not. This makes the process fundamentally different and therefore potentially serves as the basis for one being unfair while the other is not.

Advertisers stand to gain from children via purchases or purchase requests, and on the face of it, this is a plausible explanation for the intuition that child advertising is unfair. But it is not obvious why this should be. After all, parents gain from persuading their child to behave in a restaurant. It would be odd to claim that such persuasion is unfair. Granted, this is not material gain, but it is difficult to see why materiality should make a difference. This innocuous restaurant example is much less so when we imagine a parent silencing their child in a way harmful to them. This, I take it, is because we are really concerned about harm done to the child when talking about unfair persuasion. To support this claim, we can examine examples of what looks like unfairness by virtue of material gain, but which turns out to be about outcome after all. This will hopefully show that our intuitions about material gain being unfair really stem from situations in which one person's gain is the other's loss, and that the loss is the source of the unfairness.

Suppose that A covertly photographs B in the street and sell prints of B's image for large sums of money. The prints are sold to private collectors abroad, and there will be consequences for B. A has gained materially from B, yet B has not been harmed. Nonetheless, this is arguably unfair. In some ways, this mirrors child advertising insofar as B was unaware that A was taking advantage of B's doing something worthy of being photographed. But is not the explanation for this unfairness that B was not compensated for participating? The wrong of A's profiting from the photograph is surely that A profits at the expense of B's fair share? B is not worse off for having been photographed, but B is worse off relative to a fair distribution of the profit. In the exploitation literature, this is how exploitation is usually understood in cases where workers are better off for having a job, but worse off relative to a baseline of fair distribution of the product of their labour (Zwolinski 2017).

An alternative reading of this example is that B's failure to consent is what makes the process unfair. B never agreed to be photographed. This seems to mirror the problem with child advertising, which is that children cannot enter into an advertising interaction with understanding and consent. But if that is so, then we are no longer talking about material gain A's failure to ask B's consent would be unfair before A decided to sell the picture. Selling that picture is just one among a number of activities to which B failed to consent; that it involves material gain adds nothing additional to the process, it simply specifies the activity to which B did not consent.

Another case involves A profiting from selling B's private diaries after B's death. In this case, let us suppose that B cannot literally be harmed, since he is dead. Nonetheless, we might think that $\mathrm{A}$ is being unfair in profiting from B's life. The issue here is that if we assume that only the living can be harmed, we should assume that only the living can be treated unfairly, unless good reason is given for thinking that these differ. Whatever grounds we have for saying that B can be treated unfairly after his death will allow that B can also be harmed. Therefore, there is no reason to think that unfair treatment in this case is based in the harm to B.

If negative outcomes are so clearly constitutive of unfairness, why do we have such a strong intuition that A's extracting material gain from a defenceless B is unfair? I think this is because it is easy to conflate A merely gaining from B with A gaining at B's expense, where the latter case is common enough to be taken as implied when talking about "gaining from" and the like. Phrasing it as extracting material gain, as is common, fosters this conception. Earlier, I used the example of a boxer being drugged before a fight to illustrate the principle that unfairness based in outcome can be a matter of the risked, not the actual, outcome. But this analogy is guilty of implying the same idea of A's gain necessarily coming at B's expense. This is because a boxing match is what is known as a zero-sum game. A zero-sum game is one in which one side's gain necessarily means the 
other side's loss. Imagine two tribes fighting over the territorial division of an island. If one gains territory, the other necessarily loses it-this is a zero-sum game. The boxing match is a zero-sum game because one fighter can only win if the other loses. If advertising is like that, then an advertiser making material gain from a child comes at a loss to the child. This would be a matter of negative outcome, but that would be captured simply by saying that the advertiser gains from the child. (Notice that even talking about gaining from implies that one party loses out.)

Advertising is a marketplace interaction and, as such, is not bound to be a zero-sum game. Indeed, there would be no marketplace at all if many transactions were not mutually beneficial. When a consumer buys a better, cheaper lawnmower that satisfies their preference for lawnmowers because they saw it advertised, the consumer and the company are both better off. The consumer preferred to have the lawnmower than the $£ 100$ that it cost and the company preferred to have the $£ 100$. When a child goes to Disneyland and thoroughly enjoys it, Disney benefits. They make a material gain from the child, but they do not do so at the child's expense. Since advertising is not a zero-sum game, it is perfectly possible for an advert aimed at children to gain from them materially, or to seek to do so, without doing so at their expense. If, however, we think that the attempt to gain materially from children inherently brings with it risk of a negative outcome for children, then we are likely to think that such an attempt is unfair. But in that case, our intuition is again explained by the child's being at risk of a negative outcome.

This leaves us with the question of whether there are any adverts that are not harmful to children, even if they seek material gain from them, and the further question of whether child advertising as a practice could ever be such that only these benign adverts are permitted. Both are questions of outcome, but the latter is also a question of regulation. As such, unfairness only makes sense in the context of child advertising when the outcome of the practice is taken into account. The process of persuading defenceless children, even when this defencelessness is inherent to those children, is not, on its own, unfair. The process-exclusive account is therefore not the best way to support the claim that child advertising is inherently unfair. For that, we need to look to the inclusive account.

\section{The Inclusive Account}

For child advertising to be unfair on the inclusive account requires that it be inherent to the practice that it has negative outcomes, or at least carries with it sufficient risk of them. It is useful to distinguish two broad kinds of negative outcome that require different treatment. On the one hand, there are advertising encounters that leave children worse off than before the encounter. An example would be an advert for soda that causes the child to consume more sugar than they otherwise would have. On the other hand, there are advertising encounters where children might be better off than otherwise, but where they are worse off than they should be. An example would be a child who discovers a new toy that brings them pleasure, but which is significantly less entertaining than implied by an advert. This is a mutually beneficial exchange, where both parties benefit, but where one party might be said to be exploited. Such examples are common in exploitation literature. I have chosen to talk about the first kind of advertising encounter in terms of harm, and the second in terms of suboptimal market participation.

\section{Harm}

We can start by excluding from our discussion harms that have to do with the content of specific adverts. We can exclude advertising that promotes harmful products and advertising that promotes negative stereotypes, values or attitudes. The former includes the extensive debate about advertising's link to obesity (Galbraith-Emami and Lobstein 2013). The latter includes the debate about advertising's promotion of damaging gender stereotypes (Wolin 2003). In both cases, the offending adverts can, in theory, be filtered out with regulation. In the case of obesity, this has already happened in the UK, as mentioned in the introduction to this article. Using such measures to tackle stereotypes and values would be possible, but would rely on difficult conversations about whose values should take priority and would threaten to politicise child advertising discussions. Nonetheless, the offending adverts are candidates for filtering.

It might be objected that all advertising promotes some value set or some stereotypes and that this constitutes a harm. But if so, then advertising is no different to any other media or indeed to participation in any cultural activity, which always involves presenting children with some values over others, or some conception of the good life. It will not do to condemn advertising for something that is true of the much larger category of which it is a part. This would not allow us to say what is wrong with advertising as a particular practice.

Having excluded a large amount of the harm typically associated with child advertising, what is left? The main contentious area not mentioned is that which relates to consumption in general. This manifests in two ways. The first has to do with children's attitudes towards material goods. Concerns have been raised that advertising makes children materialistic (Opree et al. 2012). The second has more to do with simply increasing children's desire for things. One concern here is that increased desire for products leads to parent-child conflict (Lawlor and Prothero 2011). There is 
significant overlap between these concerns, but we will separate them for clarity of discussion. The importance of both for our purposes is that they seem to stem from the mere fact that advertising sells things, which is unquestionably inherent to it.

\section{Indirect Promotion of Harmful Products}

Before looking at the materialism critique of child advertising, we need to address a lingering concern about advertising's role in promoting harmful products, namely that it might promote those products indirectly. There is evidence that in the case of cigarette advertising aimed at adolescents, the mechanism by which the consumer is persuaded is indirect. Pechmann and Knight (2002) found that cigarette advertising primes adolescents to view peers that smoke more favourably. This indirectly promotes smoking, since those adolescents will take their behavioural cues from their positively viewed peers. Are there any such indirect effects on younger children that might make child advertising unfair? ${ }^{3}$

If there are such indirect effects, then they will need to meet the following criteria to be relevant to our argument. They must be adverts for products that are not themselves harmful, since we have established that adverts for harmful products are an easily identified subset that need not be permitted as part of the practice. Indeed, the same logic rules out specific adverts that promote harmful products indirectly, such as adverts for candy in the shape of a cigarette. If indirect harm is an inherent feature of child advertising, it will need to be inherent to advertising as a practice.

One way that this could work is if advertising to children primes them to accept advertising as such. If so, then they would be rendered more susceptible to adverts for harmful products simply by viewing adverts for harmless ones.

If child advertising has such an indirect effect, it cannot be that it primes children to accept advertising for harmful products aimed at them, since we are assuming that such adverts are not themselves a necessary feature of advertising. This leaves us with the possibility that children who have been raised on advertising will enter adolescence and then adulthood primed to accept the claims of advertising for junk food, cigarettes and so on. The worry is that we are raising children to trust advertising. Indeed, there could be an irony in this, which is that children learn to trust advertising because we have sanitised it in order to protect them, and this trust then carries over to harmful adverts once they are exposed to those adverts.

This is an interesting thought, but like so much of the discussion of child advertising, there is not yet enough evidence

\footnotetext{
${ }^{3}$ I owe thanks to Michael Hyman for raising this question.
}

to support it. And while it makes sense that teaching children to trust advertising is risky, it is also reasonable to think that suddenly exposing people to the full gamut of advertising, harmful or otherwise, when they emerge from childhood might present a greater threat of their being susceptible to its persuasion. Indeed, children might need to be exposed to advertising even when they do not understand it in order to build the foundations for their later understanding and defence.

There is certainly room for research to show that child advertising exposure primes children to accept advertising for harmful products later on, but that research does not currently exist. Child advertising could prove to be a gateway to future harm or the foundation of future defence. It would be need to be a fairly complex longitudinal study that answered these questions, and such studies are few and far between in the child advertising debate. Nonetheless, this is a promising line of enquiry that might help decide whether child advertising is inherently unfair.

\section{Materialism: A Matter Of Attitudes}

This brings us to the topic of materialism. Materialism can be thought of as a set of values or a set of attitudes towards material goods. Materialists see possessions as central to their lives, see them as essential to their satisfaction and wellbeing, and judge success in themselves and others by quantity and quality of possessions (Richins and Dawson 1992). There is evidence that advertising causes materialism in children (Buijzen and Valkenburg 2003; Opree et al. 2014) and that materialism correlates with reduced wellbeing (Dittmar et al. 2014). There are three main hypotheses to explain the connection between advertising, materialism and children's wellbeing (Opree et al. 2012). The escalation hypothesis holds that materialism increases children's desire for material objects, which results in unhappiness when this desire is unmet (Buijzen and Valkenburg 2003). The adaptation hypothesis holds that materialism raises children's expectations, which makes them dissatisfied with what they have. The displacement hypothesis, which applies equally to adults, holds that an increased focus on acquiring material goods displaces attention from activities more conducive to wellbeing or flourishing (Waide 1987).

Opree et al. (2014) found advertising's promotion of materialism to be fully mediated by increased product desire; simply wanting more material possessions led children to have materialist attitudes. Watkins et al. (2016) found evidence implicating the branded nature of advertising. If product desire is responsible, then the development of materialism becomes cyclical: wanting more makes children materialistic; being materialistic makes them want more. But advertising's link with materialism has also been attributed to its direct promotion of a materialist message (Dittmar 
2008). In reviewing the literature, Buijzen and Valkenburg (2003, p. 440f.) characterise this line of thinking as being based on the view that "Advertising propagates the ideology that possessions are important and that desirable qualities, such as beauty, success, and happiness can be obtained only by material possessions".

If advertising promotes materialism directly-that is, its content reflects materialist values and attitudes-then we can respond in the same way as in the case of advertising for specific products. We can, in theory, filter out adverts that promote such values. We could not do this if such promotion were inherent to advertising, but notice what is required for such promotion to be present. It is not that advertising promotes the idea that products are a means to substantive goods like friendship or success; it must promote the idea that products are the primary, or only, means to such goods. This is because in many cases material goods really are an appropriate means to substantive goods. Some toys lend themselves to encouraging play among friends, for example. Others help children develop their artistic abilities. Some are just plain fun, and fun in childhood is as substantive a good as any other. Material possessions help us attain substantive goods all the time. The point is that they are not the primary means to these goods, nor are they necessary in order to attain them (although, in some cases, they arguably areone cannot paint without paint brushes). But if materialism is only directly promoted by adverts that push the idea that material goods are the primary means to substantive goods, then many adverts will not be guilty of that promotion.

One way that adverts might push this idea in the context of, say, friendship would be to suggest that children who do not buy a product will lose friends, or be less popular. Such messages are already proscribed by advertising regulation in the UK. Section 5.6 of the Broadcasting Code of Advertising Practice states: "Advertisements must not imply that children are likely to be ridiculed, inferior to others, less popular, disloyal or have let someone down if they or their family do not use a product or service" (Advertising Standards Authority 2015). Measures like this could be implemented in other countries and could be developed to deal with the full gamut of materialist value promotion.

This leaves us with materialism as indirectly promoted by advertising. Insofar as it arises from simple product desire, materialism might be thought to be an inherent consequence of advertising, which inherently promotes products (or brand or services). Nairn (2014, p. 2032) refers to advertisingmaterialism-wellbeing as the "watching, wanting, wellbeing" dynamic. She points out that the evidence for advertising's direct effect on wellbeing is not forthcoming, but that there is strong evidence for both the connection of advertising to materialism in children, and the connection between materialism and reduced wellbeing.
The difficulty with using this research to decide whether advertising inherently causes materialism is indecision as to the mechanism behind this supposed connection. As we saw, some researchers put it down to product desire, others to brand specificity, and others to the content of advertising. This is made more of a challenge by the fact that advertising exposure is measured by proxy: it is assumed that television exposure predicts advertising exposure (Nairn 2014). The threat here is not that we measure exposure incorrectly, but that we do not know what kinds of adverts are responsible for materialism. More research is needed to determine the effect of specific kinds of advertising on children's materialism. If it turns out that materialism arises only from certain approaches to child advertising, then its promotion is not inherent to the practice.

There are other concerns at play in this area of research that have to do with how we think of wellbeing. On the escalation hypothesis, the concern is that children will want more things and will be denied, leading to their dissatisfaction and unhappiness. But we have to be cautious measuring children's wellbeing in terms of satisfaction. Children might be satisfied doing nothing but eating sugar and watching cartoons, and to deny them such things might leave them dissatisfied and unhappy. But that tells us little about their wellbeing. Childhood is replete with the thwarting of desires and the delaying of gratification.

The displacement hypothesis also comes with problems. It relies on discussions of substantive goods versus non-substantive goods. Friendship is substantive; the status acquired by owning expensive clothes, or the feeling of driving a sports car are not. But these kinds of value judgement are notoriously difficult to decide objectively. Criteria for them are not agreed upon. Compare this with obesity. It is scientific consensus that obesity is unhealthy. To take just one of the many examples, increased body mass index is linked to increased risk of cancer (Calle et al. 2003). Nobody would claim that cancer is constitutive of wellbeing. Materialism's connection to wellbeing is not only more empirically tenuous, but is subject to value disagreements that make it considerably less solid. This comparison serves an important lesson for advertising discussions. For it is only in the last five years that the link between advertising and obesity has been shown beyond reasonable doubt, ${ }^{4}$ and obesity was already firmly negatively linked to wellbeing. The watchingwanting-wellbeing has a long way to go before it can be taken as seriously as child advertising and obesity.

\footnotetext{
${ }^{4}$ For example, a review of the evidence in 2014 introduces its paper with the claim that "The association between television advertising and energy intake is based on a very limited set of randomized researches lacking a solid ground of first-level evidence" (Gregori et al. 2014). Since then, a number of new articles have emerged to fill that gap (Sadeghirad et al. 2016).
} 
These reflections should not lead us to dismiss the possibility that materialism constitutes an inherent harm in child advertising. They only serve to emphasise that we are not at a stage where we can confidently claim that advertising inherently causes materialism. Nonetheless, we have good reason to think that if advertising is inherently unfair to children, materialism is the reason why.

\section{Wanting More: Parent-Child Conflict}

Nairn's (2014, p. 2050) view is that "advertising seems to play a number of roles in disrupting family dynamics and that disrupted family life is unquestionably bad for children's wellbeing". The main such disruption is parent-child conflict arising from parents' need to push back against children's desire for more.

The main reason to be cautious here is similar to that just discussed. Parent-child conflict, which arises from the denial of children's desires, is not related to wellbeing in a linear way. To measure a child's wellbeing by the level of conflict with parents would lead to counterintuitive results. Children who are rarely denied unhealthy food will be worse off than children who are frequently denied it. Yet the latter parent-child relationship is likely to be characterised by more conflict. In this case, conflict is actually an indicator of wellbeing, since it represents the parent's curtailing of the child's desires, which is in their interests.

In this case, it is clear why this conflict is good for the child: they are being denied something harmful but desirable. But being denied things is arguably a good unto itself. It is a lesson in managing desire and in the way of the world: adulthood involves continual frustration of desire at the hands of fate, circumstance and authority. To say that the conflicted parent-child relationship is worse for the child than the unconflicted is to overlook the necessity of conflict in managing expectations.

Given that parent-child conflict is not inherently a compromise to wellbeing, we need to know what types of conflict are harmful and at what level. It might be that limiting advertising exposure reduces this conflict not just to a level that is acceptable in terms of harm, but one that actually represents a healthy negotiation between parent and child with respect to the child's desires. Until this is better understood, we are not in a position to declare child advertising inherently unfair on this basis. ${ }^{5}$

\footnotetext{
5 Nairn (2014) also points out that these problems become more acute in poor families. This is a further discussion, but I take such problems to arise from the intersection of children's advertising vulnerability and the families' financial vulnerability, where the latter is not inherent.
}

\section{Suboptimal Market Participation}

We have talked at points in this article about exploitation, which is often mutually beneficial, but is nonetheless unfair (Goodin 1987). Sweatshop labourers are better off employed than not, but they are nevertheless taken unfair advantage of when paid very low wages. Such cases are not best described as harmful (Valdman 2009). However, a breakdown in the process of negotiating for appropriate payment has meant that their agreed wages have not been arrived at fairly. For instance, they are not able to seek alternative employment, which would give them some bargaining power. Mutually beneficial exploitation can also occur in the consumer marketplace. Suppose that an unscrupulous car salesman exploits a customer's ignorance of the market to sell them an outdated safety device at the same price as the newer, more effective model. If that customer was totally unaware of this kind of device, they are better off as a result of buying the outdated model than none at all; but they are worse off than they should be. This is a mutually beneficial transaction, but an unfair one. In this case, an asymmetry of information corrupts the proper process for maximising one's utility in the marketplace, leading to a suboptimal outcome in the exchange.

Before looking at suboptimal marketplace participation as it applies to child advertising, we have to deal with the fact that much of young children's participation is mediated by parents, of whom children request various things [that said, children increasingly have their own income to spend as they choose (Lawlor and Prothero 2011)]. But this mediation need not prevent us talking about children as engaged in market exchanges. Rather than thinking of them as having money which they exchange for goods, we can think of their ability to request a certain number of things and having a certain amount of influence over parental purchases as a kind of currency. If, for example, a child gets one Christmas present of their choosing, then they can be said to be "spending" that one choice on a certain product. Note that this already gives reason to deny that children are not consumers at allconsumption by proxy is still consumption.

What does suboptimal market participation look like? While an exhaustive characterisation of the ways in which one can fail to maximise utility in the market is beyond the scope of this article, there are a few clear examples that we can agree are suboptimal. These include: buying something that does not perform as expected, failing to buy something at the best available price (all else being equal), failing to buy the best value incarnation of a particular product type, and not knowing of the existence of a product that one would otherwise buy. This is not an exhaustive list, but I take it to capture some of the most common suboptimal marketing behaviours. 
The accusation against child advertising is that it draws children into market exchanges for which they are not equipped, thus it necessarily, or at least regularly, gives rise suboptimal exchanges. Hence, children might frequently overestimate the quality of a toy, or they might fail to compare the options available to them and simply request whatever adverts show them. They might be better off for having seen a toy they like and requested it, but they will have failed to maximise utility. Since children are inherently lacking market competence, we might think such marketplace failure to be an inherent consequence to advertising, even if it will not occur on every advertising encounter.

One objection to this line of thinking is that it overlooks the possibility of suboptimal market participation arising from children's ignorance of products. If children are not aware of things that they might like, then they miss out on them. Hence, adverts can serve at least one function for children that they do for adults: making consumers aware of products that fulfil their wants and needs. It is not until around 12 that children engage competently in the market, fulfilling their wants and needs appropriately (Valkenburg and Cantor 2001). But while it is true that children cannot assess their own wants and needs as well as adults, and they cannot assess advertising's promise to fulfil them, that does not exclude the possibility of advertising showing them things they might enjoy. It is a mistake to claim that children are not consumers at all just because they are not mature consumers.

The addition of parental supervision or mediation is also relevant here. There is no analogue to this for adults, who are, for the most part, on their own in the marketplace. If advertising were formulated such that it consistently misled adults, for example, there would be nobody to mediate their acting on these misconceptions. But supervised children are not solo consumers. So while their advertising encounter might not itself meet the standards for an adult's, their route to purchase from that encounter is also much more strictly controlled than an adult's. We know that parental mediation determines the kinds of products children end up with: parents are less likely to acquiesce to requests for harmful products (Lawlor and Prothero 2011). At present, there is little research into children's success or failure to participate in the marketplace under their parents' supervision.

Children cannot buy everything that adverts make them want. If they could, child advertising would almost certainly be unfair, since children would make many bad consumption decisions. But this is true even without adverts. Advertising, like other areas of market participation, is something that children begin to engage in before they fully understand it. They do so under parents' supervision, protected from harm to the extent possible. They are consumers even though they lack the full range of consumer skills. What constitutes success and failure for a supervised child responding to advertising is not the same as for an adult in the same situation. The fact that children cannot maximise their utility in the market without assistance tells us little about the fairness of advertising in the context of regulation and parental guidance.

\section{Conclusion}

We have seen that of the two accounts of unfairness-process-exclusive and inclusive- the former is untenable in the context of child advertising, since there is no good reason, independent of outcome, to distinguish commercial from non-commercial persuasion. (We dismissed outcome-exclusive accounts from the outset.) This precludes our condemning child advertising without also condemning much of the persuasion that we use to improve children's welfare. The inclusive account, which makes reference to negative outcomes for children, does not end up declaring child advertising inherently unfair. Of the various negative outcomes advertising has, many are specific to certain advertising content and can be filtered out by regulation. The rest are under-researched and have yet to be shown to be inherent to advertising.

Advertising is a complex business, as is the process of exposing children to potentially harmful features of the world. We should not reach for a ban on child advertising every time some aspect of the practice is deemed controversial. To those who see child advertising as inherently unfair, any attempt to reform it is a necessary evil-it should really be banned. But when that inherent unfairness is called into question, reform of child advertising becomes genuinely optimistic. It opens up the possibility that, under the right conditions, the process can be done ethically. The attempt to regulate child advertising fairly might prove impossible for prudential reasons. It might, for example, be prohibitively resource intensive to filter out all harmful advertising; but this is not a foregone conclusion. The question can only be decided when we spend more time talking about the kinds of regulation required. Focussing on the inherent unfairness of child advertising and getting caught up in the idea of advertising comprehension as a defence against advertising threatens to distract from this conversation.

This article recommends two courses of action. First, further research needs to be done into the consumptionrelated harms such as the threat of materialism. Perhaps with just cause, these are overshadowed by discussion of child advertising for harmful products. Second, we need to explore the power of advertising regulation to eliminate harm. Banning HFSS advertising is a start, but there are many other potential sources of harm in advertising. However, in many cases we need to tread carefully_-for what 
looks like a straightforward compromise to wellbeing can actually disguise value judgements, as is the case when condemning materialism.

The case for child advertising as we now know it being detrimental to children is building, but we need to address head-on the degree to which this is caused by features inherent to the practice. The case for a ban rests on the outcome of these conversations. For if child advertising can be regulated such that it does not threaten children's vulnerabilities, then it should not be banned on fairness grounds; but if the consumption-related threats outlined are inherent to child advertising, or even if regulation cannot remedy them in practice, then a total ban grounded in a charge of unfairness should be reconsidered.

\section{Compliance with Ethical Standards}

Conflict of interest The author declares that he has no conflict of interest.

Open Access This article is distributed under the terms of the Creative Commons Attribution 4.0 International License (http://creativecommons.org/licenses/by/4.0/), which permits unrestricted use, distribution, and reproduction in any medium, provided you give appropriate credit to the original author(s) and the source, provide a link to the Creative Commons license, and indicate if changes were made.

\section{References}

Advertising Standards Authority. (2015). UK code of broadcast advertising. https://www.cap.org.uk/Advertising-Codes/Broadcast.aspx. Accessed 01 April 2017.

Beales, J. H., III. (2003). Advertising to kids and the FTC: A regulatory retrospective that advises the present. George Mason Law Review, 12, 873.

Brenkert, G. G. (1998). Marketing and the vulnerable. Business Ethics Quarterly, 7-20. https://doi.org/10.5840/ruffinx1998110.

Buijzen, M., \& Valkenburg, P. M. (2003). The effects of television advertising on materialism, parent-child conflict, and unhappiness: A review of research. Journal of Applied Developmental Psychology, 24(4), 437-456.

Calle, E. E., Rodriguez, C., Walker-Thurmond, K., \& Thun, M. J. (2003). Overweight, obesity, and mortality from cancer in a prospectively studied cohort of US adults. The New England Journal of Medicine, 348(17), 1625-1638.

Carter, O. B. J., Patterson, L. J., Donovan, R. J., Ewing, M. T., \& Roberts, C. M. (2011). Children's understanding of the selling versus persuasive intent of junk food advertising: Implications for regulation. Social Science and Medicine, 72(6), 962-968.

Dittmar, H. (2008). Consumer society, identity, and well-being: The search for the "good life" and the "body perfect". London: Psychology Press.

Dittmar, H., Bond, R., Hurst, M., \& Kasser, T. (2014). The relationship between materialism and personal well-being: A meta-analysis. Journal of Personality and Social Psychology, 107(5), 879-924.

FTC. (1978). FTC staff report on television advertising to children. Washington, DC: Federal Trade Commission.
Galbraith-Emami, S., \& Lobstein, T. (2013). The impact of initiatives to limit the advertising of food and beverage products to children: A systematic review. Obesity Reviews, 14(12), 960-974.

Goodin, R. E. (1987). Exploiting a person and exploiting a situation. In Modern theories of exploitation (pp. 171-178). London: Sage.

Gregori, D., Ballali, S., Vecchio, M. G., Sciré, A. S., Foltran, F., \& Berchialla, P. (2014). Randomized controlled trials evaluating effect of television advertising on food intake in children: Why such a sensitive topic is lacking top-level evidence? Ecology of Food and Nutrition, 53(5), 562-577.

Gunter, B., Oates, C., \& Blades, M. (2004). Advertising to children on $T V$ : Content, impact, and regulation. London: Routledge.

Jansen, L. A., \& Wall, S. (2013). Rethinking exploitation: A processcentered account. Kennedy Institute of Ethics Journal, 23(4), 381-410.

John, D. R. (1999). Consumer socialization of children: A retrospective look at twenty-five years of research. The Journal of Consumer Research, 26(3), 183-213.

Kunkel, D., Wilcox, B. L., Cantor, J., Palmer, E., Linn, S., \& Dowrick, P. (2004). Report of the APA task force on advertising and children. Washington, DC: American Psychological Association.

Lapierre, M. A. (2015). Development and persuasion understanding: Predicting knowledge of persuasion/selling intent from children's theory of mind. The Journal of Communication, 65(3), 423-442.

Lawlor, M.-A., \& Prothero, A. (2011). Pester power-A battle of wills between children and their parents. Journal of Marketing Management, 27(5-6), 561-581.

Nairn, A. (2014). Advertising and child well-being. In A. Ben-Arieh, F. Casas, I. Frønes, \& J. E. Korbin (Eds.), Handbook of child wellbeing (pp. 2031-2055). London: Springer.

Oates, C., Blades, M., \& Gunter, B. (2002). Children and television advertising: When do they understand persuasive intent? Journal of Consumer Behaviour, 1(3), 238-245.

Opree, S. J., Buijzen, M., \& Valkenburg, P. M. (2012). Lower life satisfaction related to materialism in children frequently exposed to advertising. Pediatrics, 130(3), 486-491.

Opree, S. J., Buijzen, M., van Reijmersdal, E. A., \& Valkenburg, P. M. (2014). Children's advertising exposure, advertised product desire, and materialism. Communication Research, 41(5), 717-735.

Pechmann, C., \& Knight, S. J. (2002). An experimental investigation of the joint effects of advertising and peers on adolescents' beliefs and intentions about cigarette consumption. The Journal of Consumer Research, 29(1), 5-19.

Richins, M. L., \& Dawson, S. (1992). A consumer values orientation for materialism and its measurement: Scale development and validation. The Journal of Consumer Research, 19(3), 303-316.

Sadeghirad, B., Duhaney, T., Motaghipisheh, S., Campbell, N. R. C., $\&$ Johnston, B. C. (2016). Influence of unhealthy food and beverage marketing on children's dietary intake and preference: A systematic review and meta-analysis of randomized trials. Obesity Reviews, 17(10), 945-959.

Valdman, M. (2009). A theory of wrongful exploitation. Philosophers' Imprint, 9(6), 1-14.

Valkenburg, P. M., \& Cantor, J. (2001). The development of a child into a consumer. Journal of Applied Developmental Psychology, 22(1), 61-72.

Waide, J. (1987). The making of self and world in advertising. Journal of Business Ethics, 6(2), 73-79.

Watkins, L., Aitken, R., Robertson, K., Thyne, M., \& Williams, J. (2016). Advertising's impact on pre-schoolers' brand knowledge and materialism. International Journal of Consumer Studies, 40(5), 583-591.

Wolin, L. D. (2003). Gender issues in advertising-An oversight synthesis of research: 1970-2002. Journal of Advertising Research, $43(1), 111-129$. 
Zwolinski, M. (2017). Exploitation. In E. N. Zalta (Ed.), The Stanford Encyclopedia of Philosophy. Stanford University. https://plato. stanford.edu/archives/sum2017/entries/exploitation/. Accessed 01 April 2017. 